\title{
ANÁLISE DESCRITIVA DA UTILIZAÇÃO DE METODOLOGIAS ATIVAS NO CURSO DE CIÊNCIAS CONTÁBEIS EM UMA INSTITUIÇÃO DE ENSINO SUPERIOR PRIVADA DE GOVERNADOR MANGABEIRA- BA
}

\author{
DESCRIPTIVE ANALYSIS OF THE UTILIZATION OF ACTIVE METHODOLOGIES IN AN \\ ACCOUNTING COURSE IN A PRIVATE HIGHER EDUCATION INSTITUTION OF GOVERNADOR \\ MANGABEIRA- BA
}

Caroline de Souza dos Santos ${ }^{1}$ Leonardo Souza de Almeida ${ }^{2}$

As transformações ocasionadas pela globalização têm impulsionado mudanças em todas as áreas do conhecimento, em especial nas Ciências Sociais, a exemplo das Ciências Contábeis. Faz-se necessário que os processos de ensino-aprendizagem estejam em conformidade com as constantes mudanças do meio econômico e social. Para atender a esta demanda, é preciso que a formação dos profissionais contábeis esteja alinhada às crescentes demandas do mercado de trabalho, o que implica o uso de técnicas inovadoras, capazes de formar contadores e cidadãos críticos e ativos. Neste sentido, surgem as metodologias ativas de ensino, que buscam ressignificar o processo educativo, tornando o estudante protagonista da aprendizagem. O objetivo deste estudo é descrever a utilização de metodologias ativas de ensino no curso de Ciências Contábeis em uma instituição de ensino superior privada da cidade de Governador Mangabeira-BA. Realizouse uma pesquisa descritiva e qualitativa, utilizando-se de questionários aplicados aos docentes do curso de Ciências Contábeis para coleta de dados. Os resultados demonstraram que $100 \%$ dos pesquisados afirmaram terem conhecimento das metodologias ativas de ensino, embora a grande maioria dos professores $(52,90 \%)$ opte pelas metodologias tradicionais, sendo a aula expositiva a mais empregada. A principal dificuldade encontrada para a utilização desses novos métodos foi a cultura enraizada no âmbito educacional, enquanto a principal vantagem de sua aplicação, como percebida pelos docentes, foi o aumento da atratividade para todos os envolvidos no processo. Por fim, ressalta-se a importância da metodologia ativa de ensino para a formação do profissional contábil na medida que propicia o desenvolvimento de habilidades como autonomia e senso crítico, características imprescindíveis para o exigente mundo dos negócios.

Palavras-chave. Metodologias Ativas. Ensino em Contabilidade. Contabilidade.

The transformations caused by globalization have brought about changes in all areas of knowledge, especially in the Social Sciences, as is the case in Accounting Sciences. Thus, it is necessary that the teaching learning processes be in conformity with the constant changes of the economic and social environment. To meet this demand, the training of accounting professionals must be aligned with the increasing demands of the labor market, which implies the use of innovative teaching techniques capable of forming critical accountants and citizens. In this sense, active teaching methodologies arise, which seek to re-signify the educational process, making the student the protagonist of learning. The purpose of this study is to describe the use of active teaching methodologies in the course of Accounting Sciences at a private higher education institution in the city of Governador Mangabeira-BA. The research was descriptive and qualitative and it was carried out using questionnaires applied to the professors for data collection. The results showed that $100 \%$ of the respondents had knowledge of active teaching methodologies, although the majority of professors (52.90\%) chose traditional teaching methodologies, and teacher centered methods were the most employed. According to the interviewed professors, the main difficulty was the culture rooted in the educational scope, while the main advantage was the increase of attractiveness for all involved in the process. Finally, the importance of the active teaching methodology for the formation of the accounting professionals is emphasized, as it provides skills such as autonomy and critical sense, essential for the demanding world of business.

Keywords. Active Methodologies. Accounting Teaching. Accounting.

\footnotetext{
${ }^{1}$ Graduanda do Curso de Ciências Contábeis da Faculdade Maria Milza (FAMAM) - Lattes: http://lattes.cnpq.br/9262586538241470 E-mail: Caroline.mtx@gmail.com

${ }^{2}$ Mestrando em Contabilidade pela Universidade Federal da Bahia (UFBA). Docente da Faculdade Maria Milza (FAMAM)

Lattes: http://lattes.cnpq.br/1222504334500245 E-mail: Isalmeida@uefs.br
} 


\section{INTRODUÇÃO}

As diversas mudanças ocasionadas após a globalização contribuíram para o estabelecimento de um mercado cada vez mais competitivo que exige profissionais altamente capacitados. Para atender a essa conjuntura, os cursos de graduação e pós-graduação se tornam importantes instrumentos para a preparação do sujeito para o meio laboral e para a vida.

No universo acadêmico, as Ciências Contábeis despontam como um campo do conhecimento que cuida não somente das questões econômicas e comerciais, mas também como principal instrumento de provisão de informações de qualidade, possibilitando uma gestão empresarial que traga benefícios para os usuários internos e externos.

Nesse sentido, apesar do ensino da Contabilidade ter vivenciado mudanças quanto a sua matriz curricular, o processo pedagógico manteve-se quase estático, voltado para metodologias passivas. (KAWATTA; SILVA; SILVA, 2016). Estes métodos passivos ou tradicionais geralmente são pautados na figura do educador, voltados para a memorização e repetição sistemática. Desta forma, pode inibir a aquisição de competências tidas como indispensáveis para o profissional contábil, a exemplo da proatividade, especialmente pelo fato de permitir ao educando permanecer em uma zona de conforto preestabelecida (OLIVEIRANETO; CHIORATTO, 2017).

Então, surge a necessidade da utilização de métodos inovadores que tornem o ambiente educacional propício à formação de profissionais dinâmicos e que atendam às demandas do mundo do trabalho. Nesse contexto, podemos citar a metodologia ativa, que pode ser entendida como a retirada do protagonismo do professor, de modo a tornar o estudante o centro do processo de aprendizagem, através de atividades que os levem a pensar no que está sendo feito, enfatizando a exploração de suas próprias atitudes e valores (BONWELL; EISON, 1991).

Diante deste contexto, surge a seguinte questão de pesquisa: como se dá a utilização das metodologias ativas de ensino por parte dos docentes dos cursos de Ciências Contábeis de uma instituição de ensino superior privada em Governador Mangabeira-BA?

Nessa conjuntura, o objetivo do presente trabalho é descrever a utilização de metodologias ativas de ensino dentro do curso de Ciências Contábeis, em uma instituição privada de ensino superior em Governador Mangabeira- BA.

Como objetivos específicos da pesquisa tem-se I) Identificar os tipos de metodologias de ensino frequentemente aplicadas nos cursos de Ciências Contábeis, por parte dos docentes; II) Verificar os benefícios e as dificuldades percebidas pelos docentes quanto à aplicação de métodos ativos de ensino; III) Classificar as metodologias utilizadas pelos professores nos cursos de Bacharelado em Contabilidade como metodologias tradicionais ou metodologias ativas, conforme a teoria correlata.

O estudo acerca desta temática justifica-se por ampliar a discussão sobre a formação acadêmica dos profissionais contábeis, para que esta seja aprimorada com o uso de técnicas que promovam a reflexão do sujeito, contribuindo para uma mão de obra eficaz e eficiente para o contexto laboral e para a tomada de decisões. Ademais, destaca-se a ampliação sobre a discussão das metodologias ativas de ensino dentro das Ciências Contábeis.

\section{REFERENCIAL TEÓRICO O Processo de Ensino/Aprendizagem e os Métodos Empregados}

Os termos métodos, metodologias e técnicas podem gerar confusões, em especial para iniciantes na docência ou na pesquisa, ao serem tratados como sinônimos, quando na verdade tratam de coisas distintas. O método pode ser compreendido como um procedimento organizado que conduz a um certo resultado, enquanto a metodologia se refere ao conjunto de métodos, regras e postulados, relacionandose, principalmente à objetivos educativos (FERREIRA, 2001). É possível, portanto, asseverar que a metodologia é muito mais ampla que o método, mas este faz parte do acervo instrumental ao qual o docente lança mão na execução de seu ofício. 
As metodologias de ensino são os meios que os professores utilizam para conduzirem os estudantes pelo mundo do conhecimento, podendo ser das mais diferentes formas. Neste contexto, é primordial planejar o ensino de acordo com as perspectivas dos discentes, aliando técnicas capazes de torná-los sujeitos autônomos e não meros conhecedores do assunto proposto. A educação deve relacionar-se com as experiências ou conhecimentos prévios dos indivíduos, contribuindo para o desenvolvimento da criticidade (FREIRE, 1987).

No entanto, para que isso seja possível, o professor deve sempre se atualizar por meio de capacitações diversas, para se adaptar às modificações do meio em que atua, de modo a contribuir com uma educação de qualidade (DIAS; VOLPATO, 2017). Além disso, cada docente deve buscar e explorar diversas alternativas de ensino (BONWELL; EISON, 1991).

Desta forma, para que ocorram melhorias no contexto educacional, os professores devem empregar o método mais adequado à situação vivenciada. Enquanto o uso de metodologias inadequadas pode comprometer o aprendizado, (COOK; HAZELWOOD, 2002), técnicas inovadoras e dotadas de criatividade podem proporcionar a formação de profissionais autônomos e motivados, atributos imprescindíveis para o meio laboral.

Os métodos de ensino praticados no Brasil tiveram fortes influências europeias, devido à formação histórica e cultural do país. As primeiras escolas no período colonial, jesuíticas, eram pautadas no modelo escolástico, que consistia na conciliação da fé e da razão (OLIVEIRA, 2013). Posteriormente, com as diversas revoluções ocorridas ao redor do mundo, as formas de ensino passaram a sofrer forte interferência do modelo alemão, um pouco mais liberal que o anterior (ANASTASIOU, 2001).

Com relação às metodologias de ensino atualmente empregadas, também deve-se citar a influência histórica de Paulo Freire para os moldes da educação brasileira. O educador considerava que havia dois principais modelos de educação: a bancária e a problematizada, que também podem ser denominadas como passivas e ativas, respectivamente.

A educação bancária consiste principalmente na memorização, uma vez que se baseia principalmente nos conteúdos ministrados pelos docentes, que atuam como depositários do conhecimento, e na atitude apática dos estudantes com relação ao processo. Como exemplos de técnicas de ensino que configuram a educação tradicional, podemos citar as aulas expositivas, palestras e resolução de exercícios.

De acordo com Kawatta, Silva e Silva (2016, p. 1) "no ensino tradicional o professor atua como ator principal, o que deixa a figura do aluno comprometida, uma vez que o pensamento crítico não aflora". Assim, essa forma de ensino tem se tornado cada vez mais ineficaz, devido a sua mecanicidade, que impede a exploração da criatividade do sujeito. Ainda, o método passivo tende a dificultar o desenvolvimento de competências que estimulam a formação crítica, por centralizar a figura docente no processo de aprendizagem (BORGES; ALENCAR, 2014).

Contrapondo-se a este modelo, a educação problematizada busca levar o estudante a uma aprendizagem mais significativa (ARAUJO, 2015), tornando-o sujeito ativo no processo de ensino, para que desenvolva diversas habilidades como a capacidade de interpretação, de diálogo e de resolução de conflitos, de modo a adaptar o conteúdo assimilado a sua realidade, evitando a mera memorização.

Para Freire (1987, p. 39), "a educação libertadora, problematizadora, já não pode ser o ato de depositar, ou de narrar, ou de transferir, ou de transmitir "conhecimentos" e valores aos educandos, menos pacientes, à maneira da educação "bancária", mas um ato cognoscente." Desta forma, determinado assunto não é simplesmente memorizado, mas principalmente interpretado pelo estudante.

Por outro lado, hoje a hibridização de métodos que associam mais de uma ferramenta, como por exemplo a combinação de ambientes virtuais e presenciais (YAMAMOTO, 2016), é amplamente utilizada pelos professores para aumentar a efetividade do aprendizado. Deste modo, quanto maior a diversificação do processo de ensino-aprendizagem, maiores serão as chances da eficácia dos métodos empregados, especialmente pelo fato de poder trabalhar com as diversas habilidades e sentidos dos indivíduos envolvidos no processo.

É importante frisar, ainda, que apesar de todo o planejamento que envolve a atividade de ensino, que tem como objetivo o aprendizado do discente, não é possível controlar a variável aprendizagem 
(FRANCO, 2015), uma vez que esta não depende apenas do professor, mais de uma série de outros componentes que atuam no processo, devendo este, portanto, estabelecer os métodos mais apropriados para o ambiente em que atua.

\section{Metodologias Ativas de Ensino}

A grande competitividade das organizações faz com que seja ainda maior a exigência por profissionais criativos, motivados, autônomos e proativos. Portanto, é preciso que as instituições de ensino e os docentes estejam sempre repensando as suas práticas de transmissão de conhecimento, sendo imprescindível a adaptação destas ao novo contexto socioeconômico.

Kawatta, Silva e Silva (2016) afirmam que quando confrontado com o atual dinamismo e inovação, o método tradicional, em que o aluno assume uma postura passiva ao assistir as aulas, mostra-se inapropriado. Desta forma, é primordial que o modelo educacional passe por mudanças (NASCIMENTO et al., 2016).

Neste contexto, surgem as metodologias ativas, que podem ser definidas como um meio pelo qual o discente se torna um auto aprendiz, substituindo o papel muitas vezes dominante do professor na metodologia tradicional, focando na atividade, que seria o antônimo da passividade (ARAUJO, 2015).

Outrossim, Oliveira Neto e Chioratto (2017) entendem que tal modelo educacional pode ser conceituado com base na premissa de que o estudante passa a refletir sobre o que está sendo estudado, passando a ser um sujeito consciente.

Deste modo, o estudante passa a ter percepção da sua importância no processo de aquisição de conhecimento e, então, empodera-se da sua capacidade de assimilação dos conteúdos, o que the permite absorvê-los com mais facilidade. O educando torna-se o agente principal na promoção do conhecimento, desde que seja enxergado como capaz de problematizar e solucionar os questionamentos que o processo de aprendizagem traz à tona.

É importante destacar que o método ativo pode propiciar o desenvolvimento de outras competências importantes, tais como engajamento na escrita, discussão e leitura; capacidade de análise, síntese e avaliação das ideias; valorização de atitudes e valores; e a habilidade de comparar e transmitir informações (BONWELL; EISON,1991).

Além disso, Nascimento et al. (2016) afirmam que, ao empregar-se metodologias ativas de ensino, acontecem melhorias da postura dos estudantes e nos resultados obtidos, o que aumenta a sua satisfação. Por outro lado, o método promove a integração do educando com o objeto de estudo, favorecendo a aquisição do saber.

Levando-se em consideração a interferência na motivação acadêmica das práticas pedagógicas e no consequente nível de aprendizagem, os métodos ativos promovem níveis de motivação maiores do que os métodos passivos dentro do universo contábil e, portanto, ao trazer o estudante para o centro do processo educacional, melhora o nível percebido de assimilação de conteúdo (GIBAUT, 2017).

Como principais exemplos da metodologia ativa de ensino, podemos citar: a aprendizagem baseada em problemas, que consiste na junção de três elementos: o problema, o aluno e o professor (MARTINS; FREZATTI, 2015); o uso dos diálogos sucessivos que envolve a discussão de determinados assuntos dentro de um tempo proposto (MAZZUCO; WRONSKI; BIAVATTI, 2016); a sala de aula invertida, que é pautada na aquisição de conhecimento por meio do estudo prévio do discente para posterior debate em sala; jogos de empresa, que envolvem dinâmicas em grupo para simular "empreendimentos", em cujo processo decisório os estudantes deverão participar e; o estudo de caso, que é a análise de situações e a tomada de decisões, de forma a aplicar os assuntos previamente estudados (BERBEL, 2011). Desta forma, a Figura 1 mostra algumas das técnicas de metodologias ativas mais utilizadas. 
Figura 1. Exemplos de Metodologias Ativas

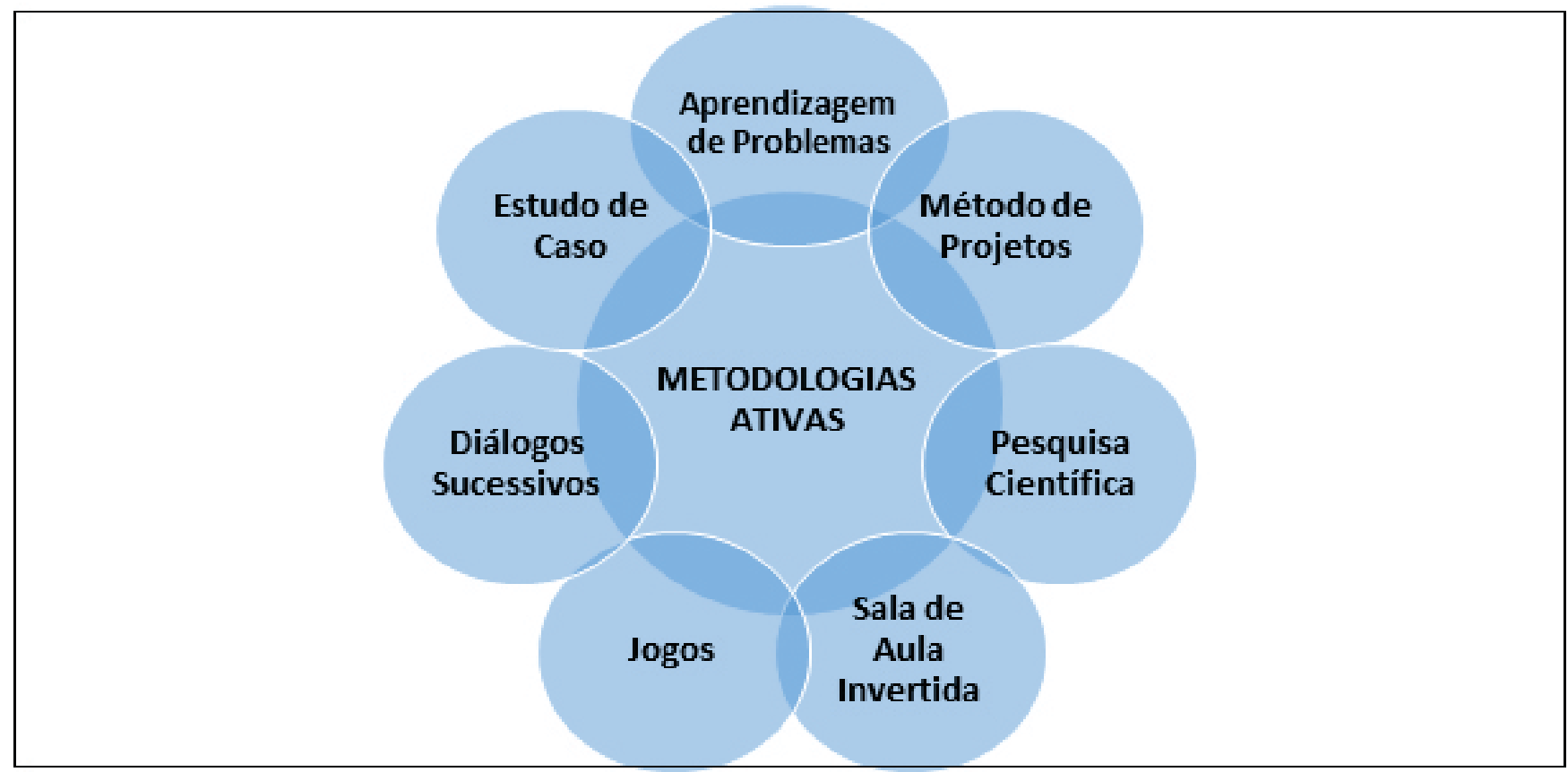

Fonte: Elaboração própria (2018).

Deste modo, são diversificadas as técnicas de ensino que podem ser desenvolvidas dentro do curso de Bacharelado em Ciências Contábeis, cabendo ao docente verificar qual ou quais destes métodos condizem com a realidade educacional vivenciada, buscando a capacitação de profissionais não somente como detentores de informação, mas principalmente como indivíduos com senso crítico capazes de solucionar situações-problema que possam decorrer do ambiente globalizado devido ao aumento da complexidade das organizações.

Em ambientes empresariais globalizados, as mudanças ocorrem a todo momento e o grande volume de dados que precisam ser analisados e sintetizados em informações úteis aos gestores é constante. Este cenário demanda profissionais com capacidade criativa e crítica, autônomos, motivados e preparados para enfrentar problemas. Estas competências podem ser trabalhadas inicialmente em sala de aula através da metodologia utilizada pelos docentes.

\section{O Ensino Superior em Contabilidade no Brasil}

A complexidade e competitividade das organizações advindas dos processos de industrialização e globalização fomentou o aprimoramento dos métodos de propagação de conhecimento utilizados pelos cursos de graduação e pós-graduação, o que resultou também na expansão do ensino superior privado no país.

Ao longo de sua existência, o curso de graduação em Ciências Contábeis, não diferentemente dos demais cursos de nível superior do país, também sofreu algumas transformações, em especial nos seus componentes curriculares, de modo a estar em conformidade com as resoluções e decretos e, ao mesmo tempo, atender aos anseios da sociedade (SOARES et al., 2011).

A evolução do ensino em contabilidade no Brasil está intimamente ligada ao desenvolvimento histórico e econômico do país. Já nos primórdios da Ciência Contábil havia uma relação intrínseca do Estado com a educação (MARRONE; RODRIGUES; PANOSSO, 2013), estabelecendo as diretrizes primordiais para a educação contábil por meio dos órgãos reguladores.

Neste sentido, um importante marco para a mudança dos moldes tradicionais de ensino foi o advento da Resolução do Conselho Nacional de Educação/ Câmara de Educação Superior (CNE/CES) 
10/2004. Através dela, que trata das diretrizes curriculares nacionais para o curso de Bacharelado em Ciências Contábeis, passou-se a ter uma maior preocupação acerca dos aspectos interdisciplinares que, por sua vez, são responsáveis por proporcionar ambientes educacionais apropriados para a formação de contadores aptos para interpretar adequadamente os demonstrativos contábeis necessários no processo decisório das entidades.

Todavia, apesar das transformações e incentivo à interdisciplinaridade, as metodologias de ensino em Contabilidade sofreram poucas alterações, sendo ainda pautadas no método tradicional. Desta maneira, Medeiros et al. (2016, p. 9) afirmam que "a abordagem tradicional de ensino, ainda hoje, está fortemente presente no cotidiano das universidades, e nos cursos superiores de Contabilidade essa é a metodologia de ensino mais utilizada."

A utilização em larga escala do ensino tradicional centrado no professor deve-se, em grande medida, à resistência de muitos docentes à utilização de métodos inovadores. Essa resistência pode estar relacionada à cultura educacional do país, ao temor às mudanças e a limitações de tempo (MEDEIROS; MOURA;ARAÚJO, 2016).

Desta forma, levando-se em consideração a escolha das técnicas empregadas, é importante ressaltar a formação pedagógica dos docentes dentro do curso de Ciências Contábeis que, geralmente, possuem o título de bacharel. Enquanto os bacharéis recebem uma formação voltada para a atuação no mercado, a dos licenciados está mais voltada para o ensino médio e superior (LAFFIN; GOMES, 2016).

Por causa desta formação, os educadores ficam expostos muitas vezes às influências dos métodos tradicionais de ensino, haja vista que a cultura do país está atrelada a uma educação bancária (FREIRE, 1987). Além do mais, a implementação de métodos tidos como inovadores requer um esforço maior do docente no planejamento de suas aulas.

A priorização por este tipo de abordagem faz com que ocorram defasagens no ensino e que a criticidade do estudante não seja explorada. Na educação bancária, de acordo com Freire (1987, p. 33), "não há criatividade, não há transformação, não há saber", ocorrendo apenas memorização. Desta forma, estes métodos têm se tornado cada vez mais ineficazes a medida que as diversas mudanças da sociedade impulsionam também estratégias inovadoras para a formação de profissionais que atendam às demandas empresariais.

\section{Estudos Recentes sobre Metodologias Ativas em Contabilidade}

A pesquisa em Ensino da Contabilidade ainda é incipiente e são poucos os trabalhos voltados às metodologias ativas de ensino dentro da Contabilidade (SANTOS; GASPARI; MARQUES, 2016). Todavia, apesar de tal escassez, alguns autores têm se dedicado a mudar este cenário, tendo em vista a representatividade que este método de ensino vem ganhando dentro da educação de nível superior.

Levando em consideração a necessidade do ensino se reinventar diante das constantes modificações da sociedade, Cruz e Wiemes (2014) abordaram a questão da necessidade de adaptação do ensino ativo diante do contexto educacional vigente e escolheram um "método ativo intermediário", pautado no nível de conhecimento dos discentes. Os resultados demonstraram que esta técnica agrega valor às aulas e aumenta a satisfação dos estudantes.

Nascimento et al. (2016) buscaram associar teoria e prática nos cursos de graduação em Administração e Ciências Contábeis por meio do uso de métodos ativos de ensino. Os resultados mostraram que houve uma melhora significativa em relação ao aprendizado e satisfação dos alunos envolvidos no projeto, especialmente por ter estimulado a capacidade de interpretação e resolução de problemas, preparando melhor os discentes para o mercado de trabalho.

Por outro lado, a dificuldade de implementação das metodologias ativas, por serem consideradas diferenciadas e muitas vezes tirarem os discentes de sua zona de conforto, também tem estimulado a discussão dos teóricos. Neste sentido, para Kawatta, Silva e Silva (2016), o principal problema está relacionado à cultura do método tradicional de ensino e o desafio dos docentes quanto à estruturação dos métodos ativos. Há, ainda, o problema do tempo considerado escasso pelos estudantes, devido às atividades diárias relacionadas às obrigações familiares ou laborais que podem dificultar a busca 
extraclasse dos assuntos abordados em sala de aula.

Nesta mesma linha de raciocínio, a pesquisa de Oliveira Neto e Chioratto (2017), realizada com uma turma do curso de graduação em Ciências Contábeis de uma instituição pública do estado de São Paulo, apontou certa resistência dos alunos às metodologias ativas de ensino, que geraram desconforto devido ao arraigo do modelo tradicional. Todavia, os estudantes, em termos estatísticos, melhoraram sua aprendizagem de forma relevante, desenvolvendo o autodidatismo e a proatividade.

Como observado, autores como Cruz e Wiemes (2014), Cittadin, Santos e Almeida (2015) e Oliveira Neto e Chioratto (2017) ressaltam as contribuições para o estudante de Contabilidade com relação à implementação de metodologias ativas de ensino em suas mais variadas formas. Foram testadas, por exemplo, a utilização de estudo de caso, sala de aula invertida e aprendizagem baseada em problemas.

Os resultados analisados sugerem que esta prática de ensino pode propiciar ao discente uma aprendizagem diferenciada, pelo fato de fazer com que o indivíduo seja o foco do processo de aquisição de conhecimento, desenvolvendo principalmente sua autonomia e criticidade.

\section{METODOLOGIA}

Este estudo de caráter descritivo tem uma abordagem qualitativa, devido a apresentar as características da população e envolver atribuição de significado para buscar a compreensão da interação educacional no curso de Ciências Contábeis numa faculdade privada localizada no município de Governador Mangabeira - BA.

Para coleta de dados escolheu-se a técnica da pesquisa de levantamento, que para Gerhardt e Silveira (2009) é aquela que busca o conhecimento direto da realidade com economia e rapidez, podendo ser estudada uma amostra ou população, utilizando-se de questionários aplicados presencialmente ou por meio do Google Form. Pode ser classificada também como um estudo de caso, na medida em que estuda a particularidade de um grupo, e os seus resultados não podem ser generalizados para outras realidades.

O questionário aplicado aos docentes envolveu 20 perguntas abertas e de múltipla escolha e foi dividido em três blocos: I - Caracterização do perfil do respondente; II - Opiniões acerca das metodologias ativas de ensino, evidenciando as convicções dos respondentes com relação ao tema e; III - Questões específicas sobre metodologias ativas, evidenciando o grau de conhecimento dos docentes sobre o assunto.

Nesta pesquisa, a amostra foi composta por um total de 12 docentes das disciplinas do eixo de Contabilidade do curso de bacharelado em Ciências Contábeis de uma instituição de ensino superior privada na cidade de Governador Mangabeira - BA. Através do horário das aulas disponibilizado pela coordenação do curso foi possível a identificação dos docentes para a aplicação do questionário. Os dados foram analisados utilizando-se o IBM ${ }^{\circledR}$ Statistical Package for the Social Sciences- SPSS ${ }^{\circledR}$, versão 22.0.

\section{RESULTADOS E DISCUSSÃO}

Após a aplicação dos questionários e tabulação dos resultados, pode-se verificar que quanto ao perfil dos respondentes, 58,33\% são do gênero masculino. Com relação à titulação, 58,33\% são mestres, enquanto $41,67 \%$ são especialistas, não possuindo nenhum docente doutor ou pós-doutor. Os dados demonstram uma predominância ainda de profissionais docentes contábeis do sexo masculino, como em Laffin (2002).

A Tabela 1 contém a análise descritiva das variáveis idade e experiência dos docentes que participaram do estudo: 
Tabela 1. Análise descritiva das variáveis idade e experiência.

\begin{tabular}{lccccc}
\hline & N & Mínimo & Máximo & Soma & Média \\
\hline Idade & 12 & 24,00 & 52,00 & 407,00 & 33,9167 \\
Experiência (em anos) & 12 & 0,50 & 15,00 & 80,50 & 6,7083 \\
N válido (de lista) & 12 & & & & \\
\hline
\end{tabular}

Fonte: Dados da pesquisa (2018).

Da análise da Tabela 1 depreende-se que os professores possuem uma média de 34 anos, variando entre 24 e 52 anos. Em relação à experiência, os dados evidenciam que em média os profissionais estão há 7 anos em sala de aula. O professor mais experiente, dentre os que participaram, tem 15 anos de profissão, enquanto o menos experiente ingressou na carreira há menos de um ano.

Dentro da realidade de estudo, $66,67 \%$ dos docentes tendem a vivenciarem a docência como sua atividade econômica principal. Esses professores que se dedicam exclusivamente à docência, sem atuar como contadores no mercado, são os principais responsáveis pelas pesquisas e trabalhos publicados dentro do universo da Contabilidade (DONATO; GARCIA; GARCIA, 2010).

Com relação ao conhecimento dos métodos ativos, 100\% dos pesquisados afirmaram terem conhecimento acerca das metodologias ativas de ensino. Caso respondessem positivamente esta questão, os docentes deveriam definir com suas próprias palavras esse método.

De maneira geral, a maioria dos professores $(91,67 \%)$ conceituaram de forma adequada o assunto. Neste sentido, um dos respondentes afirmou que a metodologia ativa é uma "forma diferenciada de lecionar quebrando a tradicional visão emissor-receptor da aula expositiva para uma construção dialogada do processo de aprendizagem". Ademais, outro docente considerou esse método como uma "prática de ensino-aprendizagem que coloca o discente como agente principal do seu aprendizado."

Ambas as colocações podem ser consideradas corretas, segundo a literatura, a exemplo de Oliveira Neto e Chioratto (2017), que consideram que a metodologia ativa de ensino foca na autoaprendizagem. Na mesma linha, Medeiros et al. (2016) consideram que este tipo de aprendizagem possibilita uma construção de conhecimento diferenciada, em que o aluno se torna o ator principal, possibilitando uma formação mais interativa. Desta forma, a metodologia ativa retira do professor o protagonismo do processo e proporciona aos estudantes autonomia nos estudos.

Sem esgotar as tentativas de testes do conhecimento docente sobre esta técnica de ensinoaprendizagem, foi inserida uma questão de múltipla escolha quanto à definição do método ativo de ensino, na qual todos os respondentes assinalaram a opção adequada, que afirmava que, neste método, o professor atua como um facilitador, estimulando a autonomia dos alunos no processo de aprendizagem.

A Tabela 2 apresenta os dados de como os docentes entraram em contato com as metodologias ativas. É importante salientar que o total dos casos (19) supera o tamanho da amostra (12), pois trata-se de uma questão que possibilita múltiplas respostas, já que é possível que os docentes tenham conhecido o tema através de mais de um meio.

Tabela 2. Onde conheceram as metodologias ativas.

\begin{tabular}{lcc}
\hline & $\mathbf{N}$ & Porcentagem \\
\hline Internet & 8 & $42,1 \%$ \\
Cursos de especialização & 1 & $5,3 \%$ \\
Livros & 5 & $26,3 \%$ \\
Palestras & 5 & $26,3 \%$ \\
Total & 19 & $100,0 \%$ \\
\hline
\end{tabular}

Fonte: Dados da pesquisa (2018). 
Os dados da tabela anterior mostram que a maior parte dos docentes conheceram o método na internet. Chama a atenção para o baixo número de respondentes que se aproximaram do objeto de estudo a partir de um curso de especialização.

A Tabela 3 apresenta a frequência com que os docentes do curso de Ciências Contábeis utilizam metodologias ativas nas suas aulas.

Tabela 3. Frequência de uso das Metodologias Ativas pelos docentes.

\begin{tabular}{lcccc}
\hline & Frequência & Percentual & Percentual Válido & Percentual Cumulativo \\
\hline Raramente & 5 & 41,7 & 41,7 & 41,7 \\
Às vezes & 3 & 25,0 & 25,0 & 66,7 \\
Muitas vezes & 4 & 33,3 & 33,3 & 100,0 \\
Total & 12 & 100,0 & 100,0 & \\
\hline
\end{tabular}

Fonte: Dados da pesquisa (2018).

Conforme mostra a Tabela $3,41,7 \%$ dos respondentes raramente utilizam metodologias problematizadoras e $25 \%$ as usam somente às vezes, perfazendo um percentual acumulativo de $66,7 \%$. Estes números indicam que os métodos passivos tendem a predominar nas aulas, já que somente $33,3 \%$ dos entrevistados aplicam frequentemente métodos ativos. Os dados são consistentes com Medeiros et al. (2016) que consideram que ainda hoje o método mais empregado no ensino contábil é a educação passiva. É preciso que os docentes entendam-se como eternos alunos em constante evolução (RODRIGUES; CERDEIRA, 2017).

Já que a maior parte dos docentes disse fazer pouco uso dessas metodologias, buscou-se entender os fatores que dificultam a sua utilização (Tabela 4). O total dos casos difere do tamanho da amostra, pois trata-se de uma questão que admite mais de uma resposta.

Tabela 4. Dificuldade no uso dos métodos ativos em sala.

\begin{tabular}{lcc}
\hline & $\mathbf{N}$ & Porcentagem \\
\hline Exige mais tempo na elaboração de suas aulas. & 3 & $15,0 \%$ \\
A cultura impulsiona o uso dos métodos tradicionais de ensino. & 9 & $45,0 \%$ \\
Nem sempre as instituições oferecem a infraestrutura adequada. & 4 & $20,0 \%$ \\
Não considero difícil a aplicação deste tipo de metodologia. & 4 & $20,0 \%$ \\
\hline Total & 20 & $100,0 \%$ \\
\hline
\end{tabular}

Fonte: Dados da pesquisa (2018).

Pode-se observar na tabela acima que a principal razão que dificulta a aplicação dos métodos ativos é a cultura enraizada (45\%). É importante destacar que nenhum docente considerou que os estudantes não se interessam por este tipo de aprendizagem, o que reforça a hipótese de que métodos inovadores seriam bem aceitos pelos estudantes. Ainda, é importante salientar que $20 \%$ dos professores não consideram difícil o uso de métodos ativos de ensino.

Os docentes também puderam pontuar as razões pelas quais consideraram vantajosa a utilização de métodos ativos. Conforme a Tabela 5, nota-se que a principal vantagem do uso desta metodologia é o fato do processo se tornar mais atraente tanto para o professor quanto para o aluno, corroborando a afirmação de que a metodologia ativa tende a aumentar a motivação para a aprendizagem (GIBAUT, 2017).

Tabela 5. Vantagens do uso da metodologia ativa.

\begin{tabular}{lcc}
\hline & $\mathbf{N}$ & $\%$ \\
\hline Ajuda na aprendizagem do aluno & 7 & $22,6 \%$ \\
O estudante se sente mais motivado & 7 & $22,6 \%$ \\
O professor ganha experiência no uso de técnicas inovadoras & 5 & $16,1 \%$ \\
O processo se torna mais atraente tanto para o professor quanto para o aluno. & 10 & $32,3 \%$ \\
Não considero fácil a aplicação deste tipo de metodologia. & 2 & $6,5 \%$ \\
\hline Total & 31 & $100,0 \%$ \\
\hline
\end{tabular}

Fonte: Dados da pesquisa (2018). 
No que se refere ao uso das técnicas de ensino, foi observado que a maioria dos docentes $(52,90 \%)$ utilizam as metodologias tradicionais de ensino, enquanto $47,10 \%$ utilizam os métodos ativos, conforme mostra a Tabela 6. Ametodologia ativa mais disseminada pelos professores é a técnica da aprendizagem baseada em problemas. Por sua vez, a aula expositiva é o meio tradicional mais utilizado.

Tabela 6. Uso das técnicas de ensino.

\begin{tabular}{|c|c|c|c|}
\hline & Classificação Técnica & $\mathbf{N}$ & $\%$ \\
\hline \multirow{7}{*}{ ATIVAS } & Sala de aula invertida & 4 & $5,90 \%$ \\
\hline & Debates & 9 & $13,20 \%$ \\
\hline & Gincanas & 1 & $1,50 \%$ \\
\hline & Aprendizagem baseada em problemas & 10 & $14,70 \%$ \\
\hline & Seminários & 7 & $10,30 \%$ \\
\hline & Jogos de empresa & 1 & $1,50 \%$ \\
\hline & Total da categoria & 32 & $47,10 \%$ \\
\hline \multirow{5}{*}{ TRADICIONAIS } & Estudo de caso & 10 & $14,70 \%$ \\
\hline & Quadro e giz & 7 & $10,30 \%$ \\
\hline & Slides & 9 & $13,20 \%$ \\
\hline & Aula expositiva & 10 & $14,70 \%$ \\
\hline & Total da categoria & 36 & $52,90 \%$ \\
\hline Total de casos & & 68 & $100,00 \%$ \\
\hline
\end{tabular}

Fonte: Dados da pesquisa (2018).

Os professores devem romper com os métodos tradicionais fortemente disseminados pelo país (KAWATTA; SILVA; SILVA, 2016), exigindo um esforço maior para inserir os discentes em situações problema que os preparem para as questões cotidianas do mercado de trabalho e desperte novas habilidades.

\section{CONSIDERAÇÕES FINAIS}

O objetivo da pesquisa foi descrever a utilização de metodologias ativas de ensino no curso de Ciências Contábeis, em uma instituição de ensino superior privada da cidade de Governador Mangabeira-BA. Para tanto, foi realizado um estudo de levantamento com caráter descritivo da instituição supracitada.

Em relação ao primeiro objetivo especifico, identificar os tipos de metodologias de ensino frequentemente aplicadas nos cursos de Ciências Contábeis, por parte dos docentes, foi observado que menos da metade dos respondentes aplicam métodos ativos com frequência, corroborando a hipótese de que a maioria dos professores tende a usar, ainda, métodos tradicionais de ensino.

O segundo objetivo foi verificar os benefícios e as dificuldades percebidas pelos docentes quanto à aplicação de métodos ativos de ensino. Neste sentido, a principal razão pela qual a aplicação dos métodos ativos pode se tornar complicada é a cultura enraizada. O processo de mudança pode gerar desconforto das partes, fazendo com que se opte então para a permanência das técnicas habituais (KAWATTA; SILVA; SILVA, 2016). Dentre os principais benefícios encontrados, destacam-se o fato do processo de ensino se tornar mais atraente tanto para o professor quanto para o aluno.

O terceiro objetivo visou classificar as metodologias utilizadas pelos professores nos cursos de Bacharelado em Contabilidade como metodologias tradicionais ou metodologias ativas. No que se refere ao uso das técnicas de ensino, foi observado que a maioria dos docentes utilizam as metodologias tradicionais de ensino, sendo a aula expositiva a mais empregada. Por sua vez, entre os docentes que 
utilizam os métodos ativos, a aprendizagem baseada em problemas é a técnica predominante.

Ainda, é válido salientar que diante do contexto atual, em que as metodologias passivas têm se tornado ineficazes (BORGES; ALENCAR, 2014), ressalta-se a importância do uso da metodologia ativa para tornar o processo de aprendizagem dinâmico e autônomo, com vistas a formar profissionais contábeis não somente detentores do conhecimento, mas capazes de interpretar as informações, de modo a contribuir positivamente para o processo decisório das organizações.

Por se tratar de um estudo de caso e de uma amostra pequena, os resultados obtidos neste trabalho não podem ser generalizados nem submetidos a análise estatística. Por esse motivo sugere-se como trabalho futuro, ampliar o tamanho da amostra, realizando estudos entre instituições de uma mesma cidade ou entre regiões distintas. Ademais, sugere-se o mapeamento da correlação entre variáveis idade, tempo de experiência profissional e o uso de métodos ativos de ensino.

\section{REFERÊNCIAS}

ARAUJO, J. C. S. Fundamentos da Metodologia de Ensino Ativa (1890-1931). In: 37a. Reunião Anual da Associação Nacional de Pesquisa e Pós-Graduação em Pesquisa, 2015, Florianópolis, SC. PNE: Tensões e Perspectivas para a Educação Pública Brasileira, Universidade Federal de Santa Catarina, Florianópolis -SC, v. 1. p. 1-15, 2015.

BERBEL, N. A. N. As metodologias ativas e a promoção da autonomia de estudantes. Semina: Ciências Sociais e Humanas, Londrina, v. 32, n. 1, p. 25-40, jan./jun. 2011. Disponível em: <http://www.uel.br/revistas/uel/index.php/seminasoc/article/view/10326/10999>. Acesso em: 13 abr. 2018.

BONWELL, C. C., EISON, J. A. Active Learning; Creating Excitement in the Classroom. ASHE-ERIC Higher Education Report No. 1. Washington, D.C.: The George Washington University, 1991.

BORGES, T. S.; ALENCAR, G. Metodologias ativas na promoção da formação crítica do estudante: o uso das metodologias ativas como recurso didático na formação crítica do estudante do ensino superior. Cairu em Revista, Ano 03, n 04, p. 119-143, jul./ago. 2014.

BRASIL. Ministério da Educação. Conselho Nacional de Educação. Resolução CNE/CES 10/2004. Institui as diretrizes curriculares nacionais do curso de graduação em Ciências Contábeis, e dá outras providências.

CITTADIN, A.; SANTOS, A. P.; ALMEIDA, J. A. M. O uso de metodologias ativas na disciplina de contabilidade e análise de custos no curso de Ciências Contábeis da UNESC. In: Seminário de Educação, Conhecimento e Processos Educativos, v. 1, 2015.

COOK, E. D.; HAZELWOOD, A. C. An active learning strategy for the classroom— "who wants to win . . . some mini chips ahoy?". Journal of Accounting Education, 2002.

CRUZ, J. A.; WIEMES, L. Incentivo à melhoria de práticas pedagógicas com a utilização do método PBL. Conhecimento Interativo, São José dos Pinhais, PR, v. 8, n. 2, p. 87-101, jul./dez. 2014.

DIAS, S. R.; VOLPATO, A. N. (Org.). Práticas inovadoras em metodologias ativas. Contexto Digital, Florianópolis, 2017.

DONATO, F. S.; GARCIA, O. P. G., GARCIA, E. Comparativo da aplicabilidade de metodologias no ensino da contabilidade em nível de graduação. In: $2^{\circ}$ Encontro de Estudantes de Ciências Contábeis, ENCICON, set. 2010.

FERREIRA, A. B. H. Mini Aurélio Século XXI Escolar: O minidicionário da língua portuguesa. 4. ed. Rio de Janeiro: Nova Fronteira, 2001. 
FRANCO, M. A. S. Práticas pedagógicas de ensinar-aprender: por entre resistências e resignações. Educ. Pesqui., São Paulo, v. 41, n. 3, p. 601-614, jul. /set. 2015.

FREIRE, P. Pedagogia do Oprimido. $17^{\mathrm{a}}$ ed. Rio de Janeiro, Paz e Terra, 1987.

GIBAUT, E. A. A sua forma de ensinar me motiva e eu percebo que aprendo? Uma análise das práticas pedagógicas e as suas consequências para a motivação acadêmica e o nível percebido de aprendizagem. Universidade Federal da Bahia, UFBA, Salvador, 2017.

KAWATTA, R. M.; SILVA, C. C.; SILVA, S. C. Dificuldades e expectativas na implementação da metodologia PBL nos cursos de Ciências Contábeis. PBL 2016 International Conference, São Paulo- SP, set. 2016.

LAFFIN, M. De Contador a Professor: A trajetória da docência no ensino superior de contabilidade. 2002. Tese (Doutorado em Engenharia de Produção) - Universidade Federal de Santa Catarina, Santa Catarina.

LAFFIN, M.; GOMES, S. M. S. Formação Pedagógica do Professor de Contabilidade: O Tema em Debate. Revista acadêmica, avaliada por pares, independente, de acesso aberto, e multilíngue: Arquivos Analíticos de Políticas Educativas, v. 24, n. 77, jul. 2016.

MARTINS, D. B.; FREZATTI, F. Problem-Based Learning no Ensino em Contabilidade Gerencial: Experiência numa Instituição de Ensino Superior. In: XV Congresso USP Controladoria e Contabilidade no Século XXI, São Paulo, SP, jul. 2015.

MAZZUCO, M. A. S.; WRONSKI, P. G.; BIAVATTI, V. T. Percepção dos alunos de ciências contábeis quanto a aplicação de diálogos sucessivos no ensino. In: XVII Congresso Nacional de Administração e Contabilidade AdCont, Rio de Janeiro, RJ, out. 2016.

MEDEIROS, J. T et al. Metodologias Ativas na Docência Contábil: Reflexões Sobre a Prática em Sala De Aula. In: Congresso Internacional de Administração. Natal, RN, set. 2016.

MEDEIROS, V. C.; MOURA, I. D. P.; ARAUJO, A. O. Metodologias ativas de ensino-aprendizagem: a experiência da aplicação dos jogos de empresas em uma turma de mestrado em contabilidade. In: Congresso Internacional de Administração, Natal, RN, set. 2016.

NASCIMENTO, E. Q. et al. Projeto integrador do curso de Administração e Ciências Contábeis: Aplicação da metodologia ativa com instrumento para a quebra do paradigma teoria versus prática. In: II Congresso de Inovação e Metodologias de Ensino, 2016.

OLIVEIRA, T. A Escolástica como Filosofia e Método de Ensino na Universidade Medieval: uma reflexão sobre o Mestre Tomás de Aquino. CEMOrOC-Feusp - Centro de Estudos Medievais - Oriente \& Ocidente, Universidade de São Paulo USP, São Paulo, 2013.

OLIVEIRA NETO, J. D.; CHIORATTO, V. H. M. Active methodology effectiveness evaluation regarding accounting students' critical and reflexive perceptions. In: 14th International Conference on Information Systems \& Technology Management- CONTECSI, 2017.

RODRIGUES, A. L.; CERDEIRA, L. Novas metodologias na didática da Economia e Contabilidade - caso do Mestrado em Ensino Português. Revista Educação em Questão, Natal, v. 55, n. 46, p. 34-58, out./dez. 2017.

SANTOS, L. A. F; GASPARI, S. S. L. C; MARQUES, M. S. Pesquisa bibliométrica sobre os métodos de ensino em contabilidade. Caderno de Administração, v. 24, n. 2, 2016.

SOARES, S. V. et al. Evolução do currículo de Contabilidade no Brasil desde 1809. Revista Catarinense da Ciência Contábil-CRCSC, Florianópolis, v. 10, n. 30, p. 27-42, ago. /nov. 2011.

YAMAMOTO, I. Metodologias Ativas de Aprendizagem interferem no desempenho dos estudantes. 2016. Dissertação (Mestrado em Administração) - Universidade de São Paulo USP, São Paulo. 